This is a pre-copyedited version of a contribution published in: Gutiérrez-Artacho J., 01vera-Lobo MD. (2017) Web Localization as an Essential Factor in the Internationalisation of Companies: An Approximation of Spanish SMEs. In: Rocha Á., Correia A., Adeli H., Reis L., Costanzo S. (eds) Recent Advances in Information Systems and Technologies. WorldCIST 2017. Advances in Intelligent Systems and Computing, vol 569. Springer, Cham. The definitive authenticated version is available online via https://doi.org/10. 1007/978-3-319-56535-4 52

\title{
Web localization as an essential factor in the internationalisation of companies: an approximation of Spanish SMEs
}

\author{
Juncal Gutiérrez-Artacho ${ }^{1}$ María-Dolores Olvera-Lobo ${ }^{2,3}$, \\ ${ }^{1}$ University of Granada, Department of Translation and Interpreting, Faculty of Translation \\ and Interpreting, C/ Buensuceso, 11, 18003, Granada, Spain \\ ${ }^{2}$ University of Granada, Department of Information and Communication, Colegio Máximo \\ de Cartuja, Campus Cartuja s/n, 18071, Granada, Spain \\ ${ }^{3}$ CSIC, Unidad Asociada Grupo SCImago, Madrid, Spain \\ \{uncalgutierrez, molvera\}@ugr.es
}

\begin{abstract}
Constant changes in the economic environment, where globalisation and the development of the knowledge economy act as drivers, are systematically pushing companies towards the challenge of accessing external markets. Web localization constitutes a new field of study and professional intervention. From the translation perspective, localization equates to the website being adjusted to the typological, discursive and genre conventions of the target culture, adapting that website to a different language and culture. This entails much more than simply translating the content of the pages. The content of a webpage is made up of text, images and other multimedia elements, all of which have to be translated and subjected to cultural adaptation. The user must never notice that the site was originally created in another language. In addition, commercial and business translation have certain particularities which must be studied and borne in mind so as to achieve the desired communication goals.
\end{abstract}

Keywords: Localization, enterprises, internationalisation, Spanish SMEs 


\section{Introduction}

Localization forms part of the group of interdependent process known by the acronym GILT: Globalization, Internationalization, Localization, Translation [1]. If we look at them individually it can be established that translation is a process by which the meaning of a written text in a source language is communicated through an equivalent text in the target language. Regarding localization, the most popular definition, put forward by the now disappeared Localization Industry Standard Association, maintains that this activity involves taking a product and making it linguistically and culturally appropriate for a locale, that is, the country and target language in which the product in question will be used and sold [2]. Although we speak about the localization of software, videogames and apps, amongst others, it is true that in the last few years we have witnessed the unprecedented growth of web localization, a communicative, technological, textual and cognitive process by which interactive digital texts (or websites) are modified for use by an international public which is not the use initially foreseen [3]. For its part, internationalization consists in identifying all local information that appears on a website, that is, that information that is dictated by the language and culture of the country where it was originally designed, for example, dates, numbers, currency, contact information, etc. These elements must be isolated and saved independently so they can be adapted to the specifications of any language. Lastly, globalization combines the processes of internationalization and localization. It consists of the design of websites that can be used in different countries with a minimum of changes. It is a concept that belongs more to the marketing than the technical department.

The success of websites as global communication platforms, the exchange of information or the selling of products and services has been pronounced in the development of localization processes, closing the gap between Internet users from different socio-cultural and linguistic contexts The economic importance of this phenomenon is increasing, and its significance is borne out by the growing body of research dedicated to localization, specialised conferences and the number of institutions offering training courses for professionals in this area.

\section{Localization and enterprises: All about their relationship}

The internationalization and localization of websites are complex and costly processes, to which many businesses are reluctant to implement them. The long-term benefits, however, far outweigh initial costs as they suppose the creation of new markets, an increase in sales, a simplification of the process of updating information and a greater speed in entering new markets, amongst other advantages [4]. In this sense, the Strategic Plan for Internationalization and Priority Markets (2014-2015) elaborated every two years by the Spanish Ministry of Economy and Competitiveness, within the Inter-ministry Group for Support for the Internationalization of Spanish Businesses, and with the participation of the private sector and the Autonomous Regions, has the main objective of driving the internationalization of the Spanish economy, improving its competitiveness and favouring the global presence of Spanish 
businesses, thus contributing to the implementation of a new model of economic growth for Spain orientated towards the exterior. Nevertheless, in relation to ecommerce and its online presence, Spanish companies still have a long way to go. In accordance with a recent report carried out by the Nominalia hosting company in $2015,36.20 \%$ of Spanish companies still lack a corporate website, although $22.41 \%$ are in possession of one or more domains while awaiting the creation of their website. Interestingly, the same study reveals how $89.6 \%$ of users consider it essential for a company to have a web presence, even if it is just for questions of image and trustworthiness. The continuous process of change in the economic environment, where the acceleration of the globalization process and development of the knowledge economy are driving forces is systematically pushing businesses towards the challenge that facing foreign markets poses.

SMEs are conscious of the fact that, as well as having a presence on the internet, it must be frequently optimized and maintained, which is why $54 \%$ already had their own website in 2015. Any business without a website will not be found on one of the most powerful marketing tools available to it. A website affords credibility and, furthermore, helps to show the success of a company. A website is also much easier to update information on its products and services than a printed brochure or catalogue. Thus, it is a good way to inform users of the new arrival of products, services, events, deals, etc. that can be offered to them [5].

The main objective of SMEs is to improve web portals: optimizing them for mobiles (only $25 \%$ of SMEs have services optimized for mobile devices Negocios.com, 2016), SEO, making company videos and creating forums. Furthermore, companies with a social network presence enjoy a greater increase in sales. That is why $42 \%$ of SMEs consider that companies without a social network profile will be left behind technologically [6]. In terms of the presence of the company on social networks, there has been a considerable increase over the last three years. The most accepted social network is Facebook.

\subsection{Web 2.0}

The Web 2.0 can be interpreted as "all those Internet utilities and services that are supported in a database, which can be modified by users, be it content (adding, changing or deleting information, or associating information to that existing), either in the way of presenting it, or in content and form simultaneously" [7]. Web 2.0 refers to a second generation web based on communities of users and a special variety of web services, such as social networks, micro blogs, wikis, and blogs, amongst others, which encourage collaboration and the easy exchange of information between users.

The tools available on the Web 2.0 can improve and increase the practical application of this internal medium both for communication and knowledge management. Regarding intelligent telephones, the use of microblogs in the company sphere could be a very interesting communication tool, both between managers and collaborators, and between people from different areas, cities, etc.

The use of social tools is totally consolidated. This also occurs with the hardware in which these social tools is deployed. In addition, new devices are constantly 
appearing, the price goes down for others and their use is increasing at an enormous rate. This all means that the use of social tools is on the increase [8].

\subsection{SMEs on Web 2.0}

Web 2.0 developments revolve around users. This type of web is comprised of tools for communication and interaction between users; they are intuitive and easy to use. This type of tool permits users to adopt a role that is more active as content managers, creators and editors, collaborating on information and giving their opinions, in this manner leaving behind the role of a simple communication receiver with a passive attitude [8].

"Enterprise 2.0 supposes strategic integration of Web 2.0 technologies in their business, intranet and extranet, taking in the development of new bidirectional communications channels via 2.0 tools, both at an internal level (between the different departments and individuals that make up the organisation) and an external level (between the enterprise and its different stakeholders, employees, shareholders, partners, clients, suppliers and others)" [10].

Enterprises 2.0 have three main tendencies [11]: a) simple and free platforms appear for expanding and giving opinions, ideas and knowledge. The clear examples are those via blogs, wikis, social networks, etc; b) there is an appearance of structures that consist in collaboration. The most well-known example is Wikipedia; and, c) ease of organising from disorder via tagging, automatic aggregators and RSS channels.

\section{Localization and translation professionals}

Starting out from this reality and the fact that the translation and localization of websites contribute towards promoting the launch towards foreign markets of Spanish SMEs, Web localization constitutes a new area of study. From a translation perspective, localization would be the equivalent of a website adjusting to the typological, discussion and gender conventions specific to the target language, adapting the website in question to a different language and culture. This means much more than simply translating the content of the pages. The content of a web page is made up of text images and other multimedia elements, all of which need to be translated and subject to cultural adaptation. Users should never notice that the site was originally created in another language. Additionally, commercial and business translation has a number of particularities that must necessarily be studied and taken into account in order to achieve the desired communication aims [12-13].

Translation professionals make up one of the basic axes of inter-linguistic mediation [14]. This task, characterised by the use of information and communications technologies, obliges them to constantly take on new challenges, in a manner that the translation market can be classified as global, decentralised, specialised, dynamic, virtual and demanding. The existence of resources and tools that facilitate their work is fundamental in order to guarantee the creation of quality products [15]. In this sense, although the Web offers translators numerous 
possibilities of documentation as it allows them to access varied information and contact with specialists, not all information originates from reliable sources.

The translation process implies, on the part of the language professional, the undertaking of different roles, the completion of different stages and the development of multiple tasks for the attainment of the conditions of the translation job in accordance with a number of quality parameters [16-22]. Localization, for its part, implicates different actors in the process, although their number can vary, from a single person responsible for the entire process, to multiple agents in large organisations, company managers, localization managers, localization engineers, terminologists, localizers, quality control operators, freelance translators, and so on. The process also varies considerably depending on the nature of the project (marketing website, web-based application, e-commerce site, etc.), technologies involved, resources available and, even, the type of translation procedure employed.

\section{Localization: A necessary tool for the globalization of SMEs}

The localization of web content is a complex process in which different subprocesses take place whose nature differs according to the context and intention, etc. The size of the project or the human/technological team that the localization company allocates to carry it out are aspects that will directly influence the roles that the translator will have to undertake. The most important component of translationlocalization activity is the human team. Different professional profiles intervene in the translation-localization process. On occasions, the same person can carry out tasks that correspond to diverse profiles. The operative deployment of the translation process is initiated with receipt and management of the job. After organising the human resources and materials the translation/localization as such will be carried out. Then comes quality control, the integration of content, the assessment of the project and, finally, the project is delivered to the client.

Localization as an economic process entails the introduction of different degrees of localization depending on the economic importance of the market or the locale. Although it is true that establishing homogenous characteristics of the process that translators face in their localizing task is complicated, it is possible to develop a series of protocols or guidelines that delimit the process and the different degrees of localization:

- Degree of localization: a) users create texts in their own language, but certain documents are found in a different language, so that only a technical adaptation is applied; $b$ ) only a part of the website is translated, with its content remaining in the language of origin, which is very frequently the case for SMEs that internationalize their products, as they only translate certain products or information, omitting relevant information on the page; c) the linguistic tools, content and all information for the target market are revised or recreated.

- Typology of localization Another interesting aspect that should be remembered by both professionals and clients before carrying out the work are localization models depending on objectives: a) unique websites: websites similar to those in the country of origin only available in a single language and with no translation; $b$ ) 
semi-localized websites: offer contact information in the country of origin but not specific contents for different countries; c) localized websites: websites localized specifically for each country but without a structural change of the pages (the most common option); d) extensively localized websites: the content completely adapts to the destination locale; $e$ ) culturally adapted websites: reflects a total immersion in the destination culture.

- Usability: Refers to the organisation if the information on the web and the methodology for enabling the user to move around the sections effectively. Content should be appropriate for the target language and/or the locale.

- Comprehensibility and perceptibility. It is vitally importance to study the characteristics of the computing environment and the profile of the country to find solutions that best adapt to the locale.

- Accessibility and textuality: Will address the parameters of cohesion, coherence, intentionality, acceptability, informativity, situationality and intertextuality of the website.

The web information within SMEs offers very important aspects such as web localization, also called e-localization [23]; it involves a concept that is quite recent, current and affords it a new perspective. This localization term does not refer to location defined as determining a delimited area, rather to translate, adapt...

The LISA organisation defines localization with these four components: linguistic, content/cultural, physical and technical. Not just to other languages, but also other currencies, symbols, culture... transferring the message to another linguistically and culturally different audience. Adapting culture in software products or web text is one of the most important factors of localization [24].

Localization is very important for businesses for promotion in different markets; for example a program that sells products in Hungary is different to one in South American countries because there are totally different terms, symbols... which could lead to offence being taken due to a different concept of a word, etc. The web localization process is understood as an adaptation procedure.

For this reason it is said that websites, more than being translated, are localized, because they are translated to a language but adapted to everything else. This contemplates almost a need for survival on the part of companies. Internet visibility is not the sole factor but it is a very important one.

At present, globalization takes in processes bigger than localization, facilitating product distribution or multilingual help to clients [25].

Internationalization has the objective of focusing on the development stage of a product that does not depend on the language that determines it, which is where the term "internationalised text" comes from, as a beginning for localizations into the maximum possible number of languages possible [26]. Another purpose of internationalization is that it is an attempt to give visibility to the information contained by the company.

What this study aims to show is the degree to which Spanish businesses are implementing their web localization, to guarantee that they are in other markets and the possibilities they have. The quality of e-commerce is not measured, rather simply the information, service and products they offer. 


\section{Methodology}

A case study has been carried out to analyse the current presence of localization within Spanish SMEs. The sample has been gathered from the selection published in April 2014 by the Circulo de Empresarios (Circle of Entrepreneurs) on the 50 best medium-sized Spanish companies [27]. All of these companies had a size of between 50 and 249 employees and a turnover higher than $€ 50$ million in 2011. For the definitive sample selection only those with a website were selected: 34 out of the total number.

Two types of indicator have been established for evaluating the sample: indicators for evaluating company websites and indicators for evaluating web localization. The first ones focus on the quality of the websites grouped into three dimensions [28]: quality of the system - website functionality, made up of four indicators; ease of access, usability, capacity for response and design; quality of the information (precision, reliability, coverage and ease of use), and quality of service (empathy, interactivity, site 'happiness' and aesthetic attractiveness). They have been evaluated with a Likert scale from 0-4: 0 (no indicator shown), 1 (shows indicator very poorly), 2 (shows indicator poorly), 3 (shows indicator well) and 4 (the indicator is shown very well).

In the web localization evaluation, translated text is as important as adaptation to the locale. The criteria are based on three dimensions: visual level (format), navigational level and localizational level (cultural adaptation). As for the previous evaluation, they have been measured on a more reduced Likert scale of $0-2$, because they involve a more specific type of characteristic: 0 (no indicator, not evaluated), 1 (indicator, poor) 2 (indicator, good).

\section{Results}

The results of the case study reveal that in terms of the first analysis carried out the quality of the system and the quality of the information have a half-acceptable score on the websites evaluated, whereas in contrast the quality of the service does not reach a minimum acceptable score. With these results it is understood that Spanish SMEs pay less attention to the user because the websites analysed frequently do not offer services according to the user type, and the interactivity of the user within the website, amongst other aspects. It has also been demonstrated that in relation to design the large majority of SMEs do not present an option to access different devices such as tablets or mobiles. 


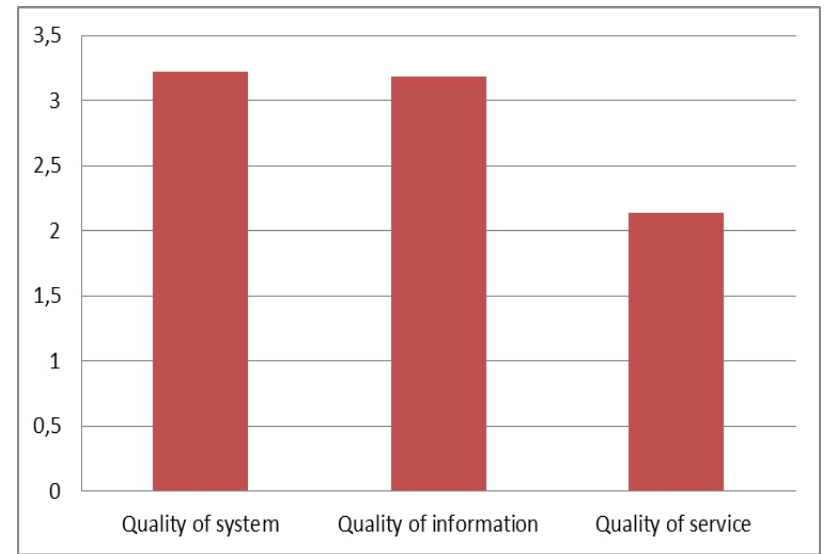

Fig. 1. Average total of dimensions in the Websites

One of the criteria that shows a lower score is trustworthiness, closely followed by ease of use. This is due to the fact that a reduced number of websites frequently update the information or indicate the date of the last update.

In terms of web localization in the 34 companies selected, it has been demonstrated that although there is a total adaptation of locational information (maps, addresses, telephone numbers, etc.), the rest of the information is drastically reduced in the translated version, with only that deemed the most important appearing in the target language. Furthermore, other links lead to websites in Spanish. In relation to this section, there are large differences between some companies and others, with completely localized websites and others with hardly any type of localization.

\section{Conclusions}

The continuous transformation in the economic environment, where the acceleration of the globalization process and development of the knowledge economy are driving forces is systematically pushing businesses towards the challenge that entering foreign markets poses. This study arises from this reality, and the fact that the translation and localization of websites contributes to the internationalization of SMEs, closing the gap between Internet users from different socio-cultural and linguistic contexts. Our aim is to visualise the importance of localization for the facilitation and improvement of the processes of externalization and globalization of Spanish SMEs. It is important to determine the most appropriate indicators in this context for measuring the quality of the localization of Spanish corporate SME websites from a technical and formal perspective, but also in terms of content (linguistic).

A study has been carried out on the websites of 34 of the most valued SMEs according to the Circle of Entrepreneurs. After analysing each of the company websites, it can be revealed that the majority of Spanish SMEs offer a good quality of systems and information on their websites, and in contrast, the quality of the service is on occasions related to obsolete sites, which are not updated over the years. 
Notwithstanding, just a third of the 34 companies in the sample analysed had links to their social network pages, and others did not even have this tool. The approach towards using 2.0 tools on the part of companies has enormous advantages, as they are both easy to use and free.

In addition, with the evaluation of the web localization it has been demonstrated that there is still a long way to go to find completely localization translated versions, showing a similar aspect to the original website. This creates a lack of trust and little chance of attracting the target market.

\section{Acknowledgements}

The authors are grateful to the Spanish "Ministry of Science and Innovation" for supporting this study, in the framework of the research Project CSO2015-64532-R, partially funded by the FEDER program of the European Union.

\section{References}

1. Cadieux, P.; Esselink, B.: GILT: Globalization, Internationalization, Localization, Translation. Globalization Insider, 11 (1.5): 1-5 .(2004).

2. LISA. Localization Industry Primer. Geneva: Localization Industry Standards Association. (2003)

3. Jiménez-Crespo, M. A.: Translation and Web Localization. New York: Routledge (2013).

4. Corte, N.: Localización e internacionalización de sitios web. (2002).

5. Zthae Pymes Blog: ¿Por qué es necesario tener una Página Web para mi negocio? Zthae Pymes Blog - Alojamiento Web y Diseño. (2016). Available at: http://www.zthaepymes.com/blog-alojamiento-web/index.php/2-uncategorised/28-por-quees-necesario-tener-una-pagina-web-para-mi-negocio.

6. Negocios.com: Sólo el 52\% de las pymes españolas tienen página web. (2016). Available at: http://www.negocios.com/noticias/52-pymes-espanolas-pagina-web-04112014-1229.

7. Ribes, X.: La Web 2.0. El valor de los metadatos y de la inteligencia colectiva. Telos (2007)

8. Alles, M.: Social media y recursos humanos, Ediciones Garnica. (2012)

9. Luna Huertas, P.; Ruiz del Castillo, J.C.; López Jiménez, D.: La Web 2.0 en el entorno empresarial: resultados derivados de un estudio empírico efectuado entre universitarios. Anales de estudios económicos y empresariales, XXI (21) (2011)

9. Ruiz del Castillo, J.C.; Luna Huertas, P.: La web 2.0 en el entorno empresarial: Socializando las Pymes. Pixel-Bit: Revista de medios y educación, (45) (2014).

10.McAffe, A.P.: Enterprise 2.0: The Dawn of Emergent Collaboration. MIT Sloan Management Review, pp.21-28. (2006).

11.Zhu, P.: On the Right Strategies for Translating Business \& Technical Information. Journal of Education and Social Science 2 (1): 61-70. (2015).

12.Zhu, P.: Translation Criteria: How They May Affect International Business. Journal of Technical Writing and Communication 45 (3). (2015)

13.Muñoz Martín, R.: Leave no stone unturned On the development of cognitive translatology, Translation and Interpreting Studies, 5 (2): 145-162 (2010).

14.Olvera-Lobo, M.D.; Castro-Prieto, R.M.; Quero Gervilla, E.F.; Muñoz Martín, R.; Muñoz Raya, E.; Murillo Melero, M.; Senso Ruiz, J.A.; Domínguez-López, C.: Translator Training 
and Modern Market Demands. Perspectives: Studies in Translatology 13 (20): 132-142. (2005)

15.Olvera-Lobo, M.D.; Castro-Prieto, R.M.; Quero Gervilla, E.F.; Muñoz Martín, R.; Muñoz Raya, E.; Murillo Melero, M.; Senso Ruiz, J.A.; Robinson, B.: A profesional approach to translator training (PATT) Meta, Journal des traducteurs, 52 (4): 517-528. (2007).

16.Olvera-Lobo, M.D.; Castro-Prieto, R.M.; Quero Gervilla, E.F.; Muñoz Martín, R.; Muñoz Raya, E.; Murillo Melero, M.; Senso Ruiz, J.A.; Robinson, B.; Conde-Ruano, T.: Student satisfaction and perceived improvement with a Web-based collaborative work platform. Perspectives: Studies in Translatology, 15(2): 106-122. (2007)

17.Olvera-Lobo, M.D.; Castro-Prieto, R.M.; Quero Gervilla, E.F.; Muñoz Martín, R.; Muñoz Raya, E.; Murillo Melero, M.; Senso Ruiz, J.A.; Robinson, B.: Student Satisfaction With A Web-Based Collaborative Work Platform. Perspectives: Studies in Translatology, 15 (2): 106-122. (2008).

19.Olvera-Lobo, M.D.; Castro-Prieto, R.M.; Quero Gervilla, E.F.; Muñoz Martín, R.; Muñoz Raya, E.; Murillo Melero, M.; Senso Ruiz, J.A.; Robinson, B.: Teleworking and collaborative work environments in translation training. Babel. International Journal of Translation, 55 (2): 165-180. (2009)

20.Olvera-Lobo, M.D.; Gutiérrez-Artacho, J.: Initiatives and evaluation of teachinglearning process in translation training. En: Garant, M. (ed.) Current trends in translation teaching and learning. Helsinki: University. pp.79-95. (2011)

21.Olvera-Lobo, M.D.; Gutiérrez-Artacho, J.: Web 2.0 technologies in the Translator Training. 6th International Conference on Education and New Learning Technologies. EDULEARN14 Proceedings. Barcelona: IATED Academy (2014).

22.Robinson, B.; Olvera-Lobo, M.D.; Gutiérrez-Artacho, J.: The Professional Approach to Translator Training Revisited. From the Lab to the Classroom and Back Again: Perspectives on Translation and Interpreting Training. New Trends in Translation Studies Series. Frankfurt am Main: Peter Lang (2016).

23.Cronin, M.: Translation and Globalization, Londres: Routledge. (2003).

24.Lommel, A.: The Globalization Industry Primer: An Introduction to preparing your business and products for success in international markets. The Globalization Industry Primer: An Introduction to preparing your business and products for success in international markets, p.70. (2007).

25.Jiménez Crespo, M.A.: El proceso de localización web : estudio contrastivo de un corpus comparable del género sitio web corporativo. Granada: Universidad de Granada (2008).

26.Pym, A.: Localization from the Perpective of Translation Studies: Overlaps in the digital divide? In Conferencia SCALLA 2004. (2004).

28.Círculo de Empresarios: Top 50 de la empresa mediana española Selección de casos de éxito. Journal of Chemical Information and Modeling, 53(9), pp.1689- 1699 (2014).

29.Chua, A.; GOH, D.; ANG, R.: Web 2.0 application in government web sites: Prevalecence use and correlotaions with perceived web site quality. Journal Information Review, pp.175195 (2012). 